\title{
Gap Mesh Wire Control on Nano-Particles Growth
}

\author{
Ahmed Rida Galaly 1,2 \\ ${ }^{1}$ Department of Environment and Health Research, the Custodian of the Two Holy Mosques Institute for Hajj \\ and Umrah Research, Umm Al-Qura University, Makkah, KSA \\ ${ }^{2}$ Physics Department, Faculty of Sciences, Beni-Suef University, Beni-Suef Governorate, Egypt \\ Email: ahmed galaly@yahoo.com
}

Received 20 April 2015; accepted 27 July 2015; published 30 July 2015

Copyright (C) 2015 by author and Scientific Research Publishing Inc.

This work is licensed under the Creative Commons Attribution International License (CC BY).

http://creativecommons.org/licenses/by/4.0/

(c) (i) Open Access

\section{Abstract}

The influence effect of different holes per inch on the plasma parameters and particle growth has been studied by compression between two different gap Aluminum meshes of $3 \mathbf{~ m m}$ width, and 8 holes per inch ( $8 \mathrm{~h} / \mathrm{in})$ and $0.3 \mathrm{~mm}$ width and 20 holes per inch $(20 \mathrm{~h} / \mathrm{in})$ at very low pressure. The perforated aluminum mesh with small diameter holes $20 \mathrm{~h}$ /in shows a better glow discharge stabilization than mesh with large diameter holes 8 h/in. For both 20 h/in and 8 h/in, sharp axial decrements for electron Temperature $\left(T_{e}\right)$, where $T_{e}$ decreased from 5.2 to $3.8 \mathrm{eV}$ for $8 \mathrm{~h} / \mathrm{in}$, from 2.75 to $1.8 \mathrm{eV}$ for $20 \mathrm{~h} / \mathrm{in}$. In contrast sharp axial increments for electron density $\left(N_{e}\right)$, whereas $N_{e}$ increased from $0.9 \times 10^{9}$ to $20 \times 10^{9} \mathrm{~cm}^{-3}$ for $8 \mathrm{~h} /$ in and from $8 \times 10^{9}$ to $42 \times 10^{9} \mathrm{~cm}^{-3}$ for $20 \mathrm{~h} / \mathrm{in}$. Silicon wafer [100] was exposed directly behind the meshes to realize nano-particle growth in sputtering discharge, where there are two different particles shapes: spherical shape particles produced by $20 \mathrm{~h} / \mathrm{in}$, and filamentary-shaped fractal particles formed by $8 \mathrm{~h} / \mathrm{in}$. The particle radius growth for $20 \mathrm{~h} / \mathrm{in}$ was in the range of $4.67-301 \mathrm{~nm}$ during exposure time 40 - $95 \mathrm{~min}$, and for $8 \mathrm{~h} /$ in were in the range of $9.2-28.8 \mathrm{~nm}$ during exposure time $60-95 \mathrm{~min}$.

\section{Keywords}

Perforated Aluminum Meshes, Plasma Parameters, Particle Growth

\section{Introduction}

In the recent years, a gas discharge plasma application has rapidly unlimited due to the great chemical freedom offered by the non-equilibrium aspects of the plasma. Gas discharge plasma presents considerable interest for a wide range of applications such as etching, coating, air pollution control and many other applications [1] [2]. 
The perforated aluminum, copper, and stainless steel were studied in many articles, thorough production of glow discharge by using a combination of fine wire mesh and perforated of different materials as electrodes were investigated. In addition, the effect of frequency and pulse supply on the stability of glow discharge was also studied [3] [4].

Particulate contamination of thin films is a concern in many industries, including semiconductor manufacturing [5]. Many researchers observed particle growth in the gas phase for all the sputtering targets, and it indicated that particles formation required a low vacuum base pressure [6].

Coating process through the particle growth in plasma interaction plays vital roles in numerous observed phenomena in the space environment, whose scope in the industrial laboratory has grown rapidly in recent times to include such diverse areas as materials processing and microelectronics [7].

In the present study, the discharge gap represented by perforated aluminum mesh with different fine holes as a power electrode is introduced. The basic idea is that the perforated meshes (consists of a series-parallel arrangement of small holes with sharp edges) have an important factor on the plasma parameters and the particle growth mechanisms. Moreover the growth of particles formed due to sputtering discharge has been carried out and investigated, using different meshes; mesh with small hole width represented by 20 fine holes per inch (20 $\mathrm{h} / \mathrm{in})$ and mesh with large hole width represented by 8 fine holes per inch ( $8 \mathrm{~h} / \mathrm{in})$.

\section{Experimental Setup}

The glow discharge plasma chamber was made of stainless steel with a length of $40 \mathrm{~cm}$ and a diameter of $28 \mathrm{~cm}$. This chamber consists of two Co-planar sputtering targets made up of one copper as an anode electrode and different Aluminum meshes as a cathode (power) electrode, and each of them have a diameter of $5 \mathrm{~cm}$. It contained four windows with thickness of about $3 \mathrm{~cm}$ and diameter of about $12 \mathrm{~cm}$ in different levels, two of them Pyrex glass windows and the two others for the gas in, gas out, the two electrodes and the double probe as shown in Figure 1.

The systems have been tested with the pressure of $6 \times 10^{-5}$ mbar. An ultra low frequency (ULF) power supply of one KHz frequency, few hundred Volts and $50-100 \mathrm{~mA}$ currents to produce ultra low frequency of plasma (ULFP) discharge current, where the plasma parameters were measured using double Langmuir probe at very low gas pressures $0.6 \mathrm{mbar}$, and the distances between the two circular electrodes were separated by small distance $5 \mathrm{~mm}$ and were placed normal to the formed plasma, where the interested regions over the perforated aluminum (Al) mesh represent the power electrode with different fine holes, which introduced as a series-parallel arrangement of small holes with sharp edges. Two different kinds of $\mathrm{Al}$ meshes to give a variety sputtering discharge, with small hole width and more space between mesh wires represented by 20 fine holes per inch (20 $\mathrm{h} / \mathrm{in}$ ), and large hole width and less space between mesh wires represented by 8 fine holes per inch ( $8 \mathrm{~h} / \mathrm{in})$ as shown in Figure 2(a) and Figure 2(b).

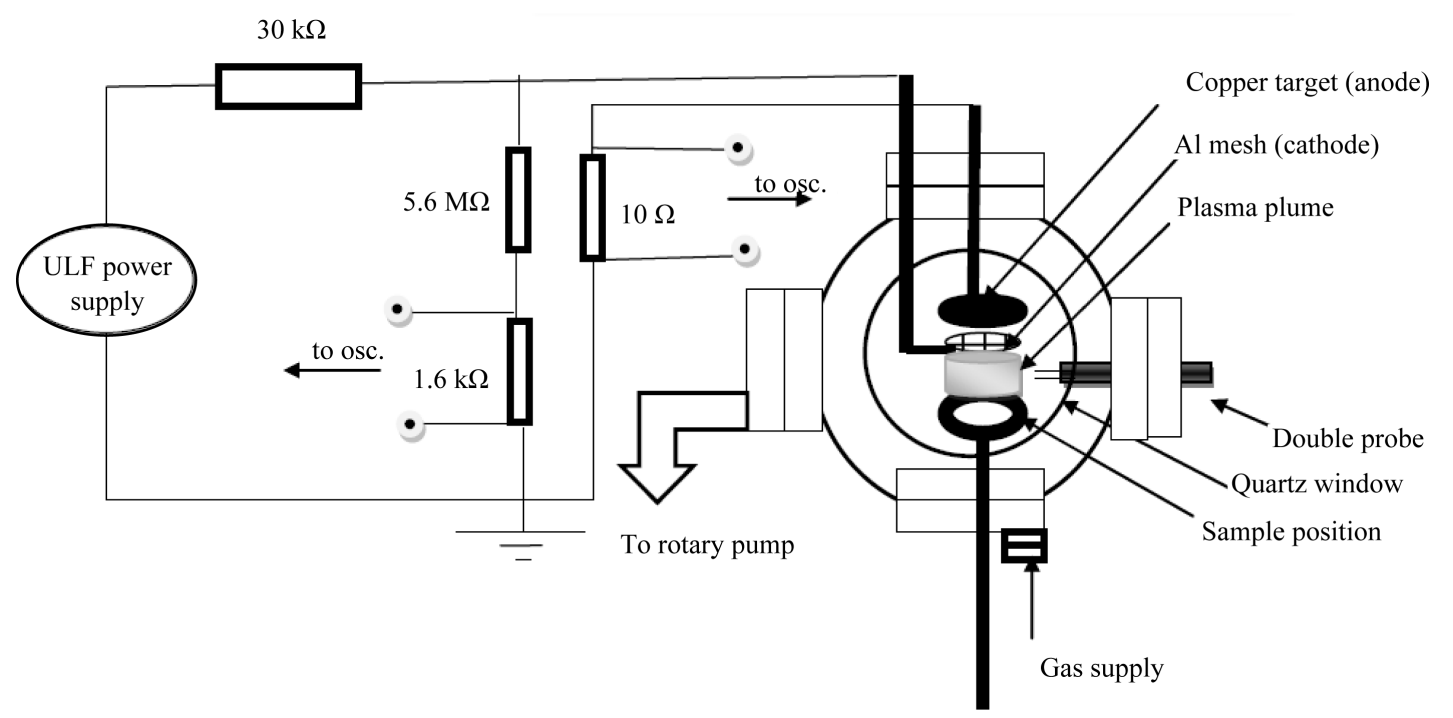

Figure 1. The diagram of the experimental set-up. 


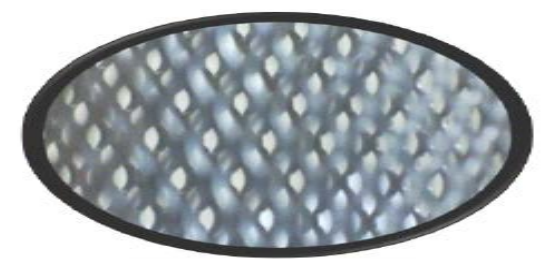

(a)

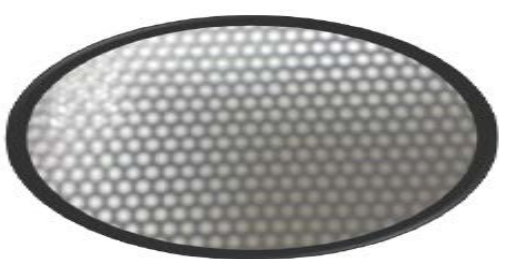

(b)

Figure 2. (a) and (b): Aluminum Meshs with different number of holes per inch, (a) $\mathrm{Al}$ mesh of $3 \mathrm{~mm}$ width of hole and 8 holes per inch; (b) Al other mesh of $0.3 \mathrm{~mm}$ width of hole and 20 holes per inch.

\section{Results and Discussion}

\subsection{The Temporal Variation of ULFP Discharge Current and Breakdown Voltage}

The electrical characteristics of the glow discharge are studied the temporal variation of (ULFP) discharge current [8] at different applied voltages and at low applied pressure $(0.6 \mathrm{mbar})$ for pure argon, where glow discharge is found to be stable only in low-pressure discharge [9] this is because when the pressure is rising, the discharge shifts to sparks and arc and thus, making it impossible to uniformly process an object [10]. The interested regions under investigation are the regions (over the $\mathrm{Al}$ mesh) which are the most intense glow zone for studying particle growth process in sputtering discharge. As shown in Figure 3, Figure 4 that the lowest voltage for starting the plasma for perforated aluminum mesh with $20 \mathrm{~h} / \mathrm{in}$ (small hole width (D) and more space between mesh wires (l)) in the range of 164 volts, but the starting potential for $8 \mathrm{~h} / \mathrm{in}$ in the range of 251 volts. For both cases the temporal variation of the ULFP discharge current increases with increasing the applied voltage, and increasing for $20 \mathrm{~h} / \mathrm{in}$ more than for $8 \mathrm{~h} / \mathrm{in}$.

Moreover one mode (peak) signal at low applied voltage and two modes signal at high applied voltage appeared. As expected more holes sufficient to cause ionization of the gas due to the penning effect in the surrounding area of the sharp edges, and leads to a production of higher local electric field strength for $\mathrm{Al}$ mesh with more holes [11].

In the present work, one mode (one peak i.e. signal with one maxima) can be obtained when small voltages were applied 164 volts for $20 \mathrm{~h} / \mathrm{in}$ and 251 volts for $8 \mathrm{~h} / \mathrm{in}$. As the applied discharge voltage is increased, the current temporal (with time) increased, and two modes (two maxima) were observed 172 volts for $20 \mathrm{~h} / \mathrm{in}$ and 276 volts for $8 \mathrm{~h} / \mathrm{in}$. It is concluded that as the applied voltage increased, the ion saturation current increased in the two modes rather than in the one mode; henceforward the electron density increased. Moreover the value of $\Delta V_{a}$ decreased in the two modes than in the one mode, thus the electron temperature decreased. Therefore in sputtering discharge, the two modes are rather suitable for particle growth process, which require high density and low temperature [12].

\subsection{The Effect on Plasma Parameters}

\subsubsection{I-V Curves of the Double Probe}

The advantage of using a double probe is that it has a negligible influence on the plasma and it produces reliable temperature and density measurements. Due to the theory of the double probe was discussed before [13]. Figure 5 show the current-voltage (I-V) characteristic curves of typical examples of the double probe for Ar discharge, at axial position $4 \mathrm{~mm}$ from the center of cathode (i.e. its parallel to the direction of the electric field lines) for two different perforated aluminum meshes $20 \mathrm{~h} / \mathrm{in}$ and $8 \mathrm{~h} / \mathrm{in}$, at low pressure $0.6 \mathrm{mbar}$. The figure shows that the ion saturation current of the probe for different perforated aluminum meshes is increased by increasing the number of holes per inch.

Where the measurements show that the ion saturation current of the probe is increased for $20 \mathrm{~h} / \mathrm{in}$ more than 8 $\mathrm{h} / \mathrm{in}$. Since at low pressure, the probability of electron ionizing collisions with atoms will decrease (i.e. the mean free path will increase), large value of the discharge voltage will be required to maintain the discharge and a small discharge current $I_{a}$ is expected. As numbers of holes per inch increases, the electron-atom ionizing collisions increase. Thus, more electrons and positive ions are produced and consequently, the discharge current is increased at the same applied voltage. 


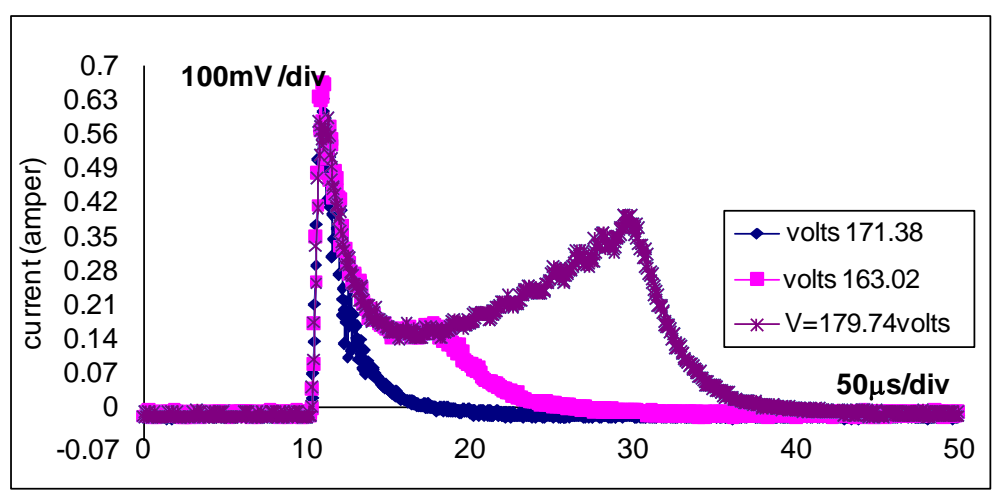

Figure 3. The temporal variation of the ULFP discharge current for $20 \mathrm{~h} / \mathrm{in}$.

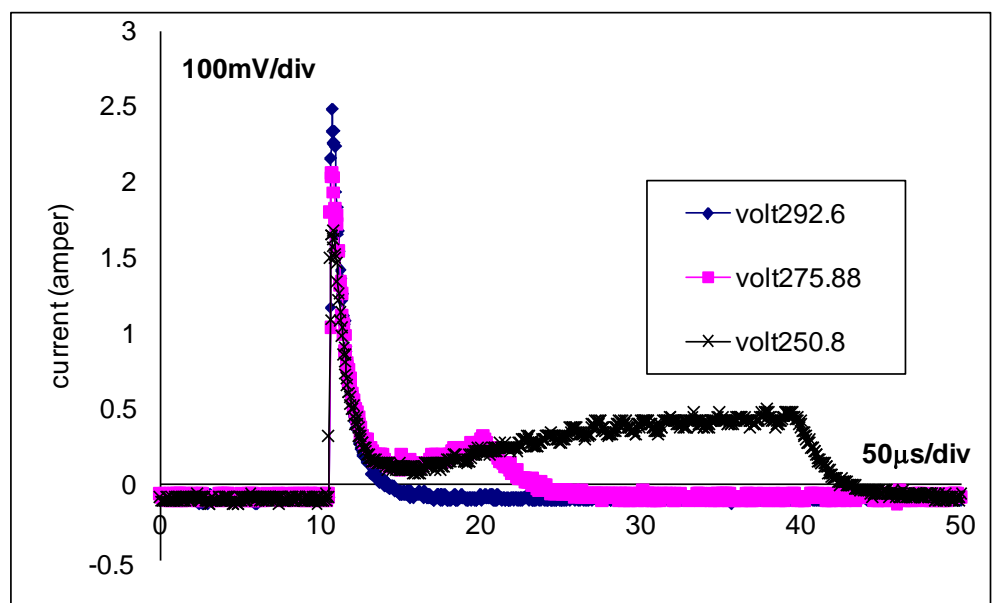

Figure 4. The temporal variation of the ULFP discharge current for 8 h/in.

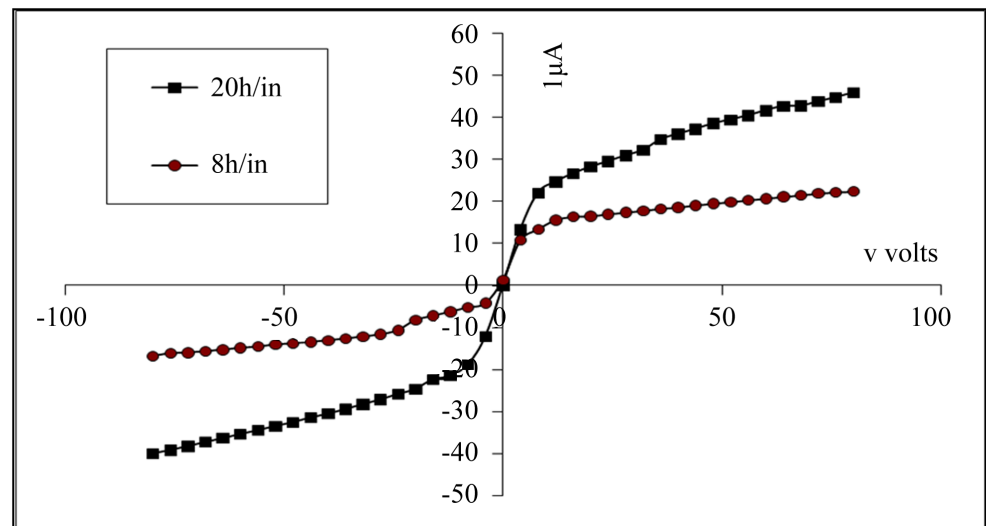

Figure 5. The I-V curves of the double probe for meshes with $20 \mathrm{~h} / \mathrm{in}$ and 8 $\mathrm{h} / \mathrm{in}$ at $4 \mathrm{~mm}$ axial distance for Ar discharge (at $P=0.6 \mathrm{mbar}$ ).

\subsubsection{The Temperature and Density Distribution}

The electron temperature using the double probe method [14] [15], can be calculated using relation (1):

$$
T_{e}=\frac{1}{4} \cdot \Delta V_{a} \cdot F\left(\frac{S}{X}\right)
$$

where $\Delta V_{a}$ is the voltage difference. The correction factor $F(S / X)$ was introduced since the ideal double probe 
characteristic is extremely difficult to obtain (experimentally) because of the sheath formation around the probe surface. The correction factor is given by (2):

$$
F\left(\frac{S}{X}\right)=\frac{1-0.85(S / X)}{1+0.5(S / X)}
$$

where $S, X$ are slopes].

The plasma density $N_{e}$ was measured using the double probe I-V characteristic curve for each region in the glow discharge. $N_{e}$ was calculated using formula (3),

$$
N_{e}=\frac{I_{i}}{e\left(2 k T_{e} / m_{i}\right)^{1 / 2} \cdot A_{p}}
$$

where $I_{i}$ is the ion current, $A_{p}$ is the area of the probe and $T_{\boldsymbol{e}}$ is the electron temperature which was determined previously by Equation (1).

Figure 6 shows the temperature distribution for meshes with 20 h/in, and 8 h/in at axial position $4 \mathrm{~mm}$ from the center of cathode mesh at low pressure $0.6 \mathrm{mbar}$ Ar pressure. A sharp axial decrements for electron Temperature $\left(T_{e}\right)$, where $T_{e}$ decreased from 5.2 to $3.8 \mathrm{eV}$ for $8 \mathrm{~h} / \mathrm{in}$, from 2.75 to $1.8 \mathrm{eV}$ for $20 \mathrm{~h} / \mathrm{in}$. Generally the decrements in the electron temperature with faraway axial of the cathode due to the increasing in the sheath length around the mesh wire, moreover temperatures for mesh with $20 \mathrm{~h} / \mathrm{in}$ is less than those of $8 \mathrm{~h} / \mathrm{in}$, may be due to the sheath length $(\lambda)$ around the mesh wires and the space between mesh wires $(l)$ are also critical factors determining the electron temperature in region over the mesh. Roughly, the temperature decreases when the ratio of $\lambda$ to $l$ increases and the temperature becomes minimal when $2 \lambda$ is comparable to $l$ [16].

Figure 7 shows that the axial distribution of electron density have a maximum values near the mesh and begin to decrease due to the ion saturation current of the double probe have a maximum value near the mesh and decrease sharply moving faraway the mesh, where the ion density $N_{i}$ is directly proportional to the ion saturation current. Also the figure show a sharp axial increments for electron density $\left(N_{e}\right)$, whereas $N_{e}$ increased from $0.9 \times$ $10^{9}$ to $20 \times 10^{9} \mathrm{~cm}^{-3}$ for $8 \mathrm{~h} /$ in and $8 \times 10^{9}$ to $42 \times 10^{9} \mathrm{~cm}^{-3}$ for $20 \mathrm{~h} / \mathrm{in}$. generally the density distribution for mesh with $20 \mathrm{~h} / \mathrm{in}$ is more than those of $8 \mathrm{~h} / \mathrm{in}$ may be due to more oxidation and ionization beside the mesh wire for $20 \mathrm{~h} / \mathrm{in}$ due to the more edges of the holes than $8 \mathrm{~h} / \mathrm{in}$.

\subsection{Particle Growth in Different Mesh Control Sputtering Discharge}

Due to use a variety of aluminum target mesh control as electrode (20 h/in and 8 h/in) In our sputtering discharge, an observation of two different kinds of Particles growth on Si-sample substrate formed in the gas phase as shown in Figure 8 and Figure 9. By using scanning electron microscopy with scan size of $10 \times 10 \mu \mathrm{m}^{2}$ for different exposure time and for different mesh control, we notes that the growth rate varies widely according to the two different gap mesh wire of cathode configuration, where for $20 \mathrm{~h} / \mathrm{in}$ configuration a compact shape that is nearly Spherical shape particle were produced as shown in Figures 8(a)-(c), while for $8 \mathrm{~h} /$ in configuration a

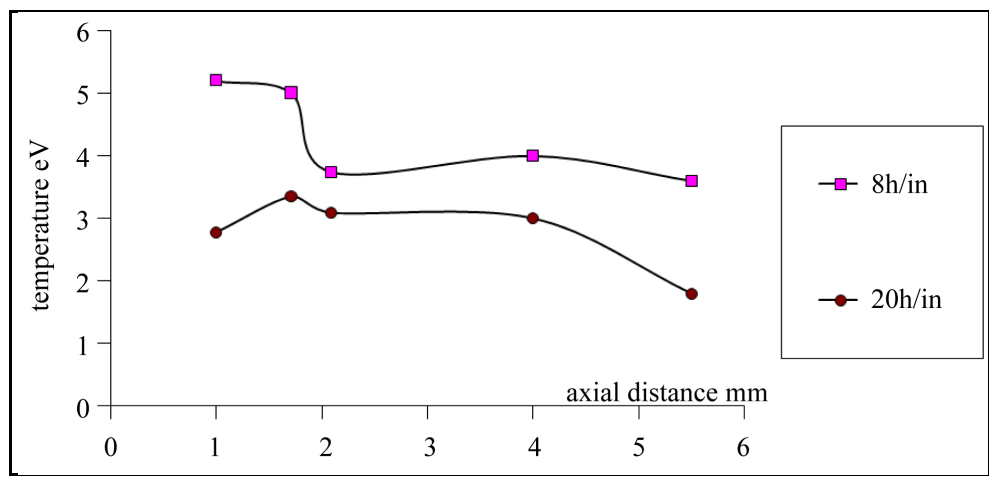

Figure 6. The temperature distribution at axial position $4 \mathrm{~mm}$ from the center of cathode for meshes with $20 \mathrm{~h} / \mathrm{in}$ and $8 \mathrm{~h} / \mathrm{in}$ for Ar discharge (at $P=0.6$ mbar). 


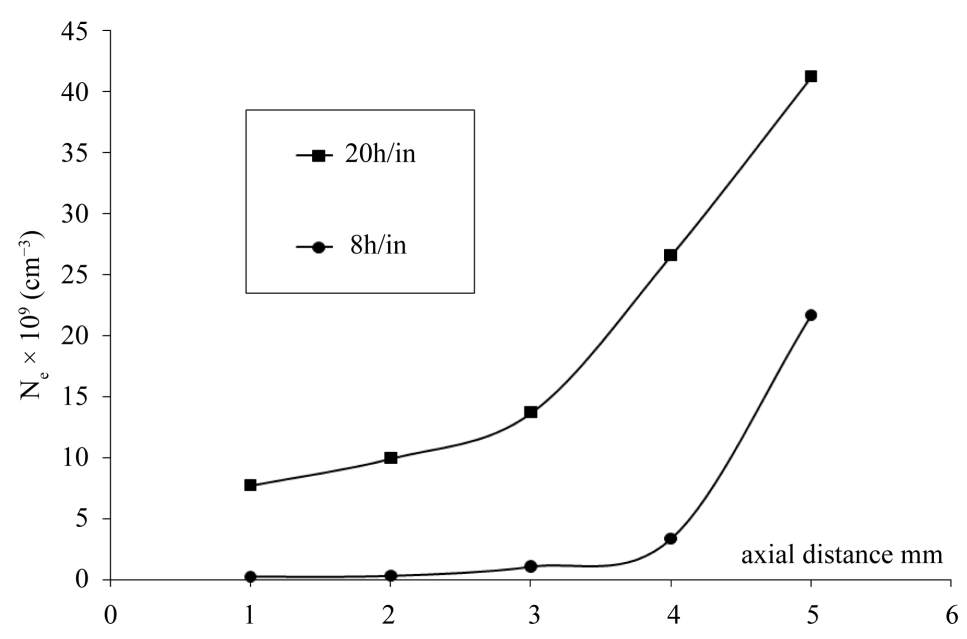

Figure 7. The density distribution at different axial distance for meshes with $20 \mathrm{~h} / \mathrm{in}$ and $8 \mathrm{~h} / \mathrm{in}$ for Ar discharge (at $P=0.6 \mathrm{mbar}$ ).

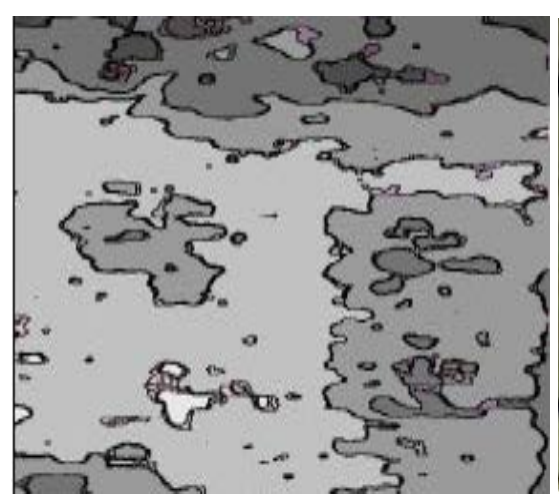

(a)

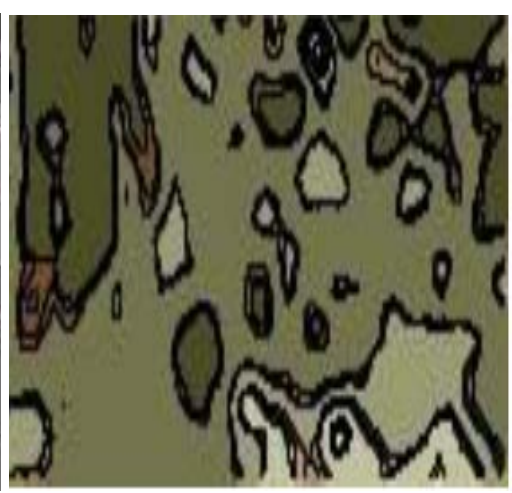

(b)

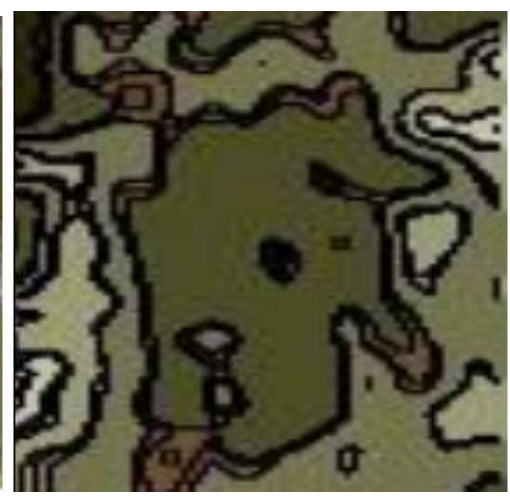

(c)

Figure 8. (a), (b) and (c): JSMI for Si wafer by $\mathrm{Al}$ mesh with $8 \mathrm{~h} / \mathrm{in}$ after coating process at room temperature with scan size of $10 \times 10 \mu \mathrm{m}^{2}$. (a) $t=60 \mathrm{~min}$; (b) $t=80 \mathrm{~min}$; (c) $t=90 \mathrm{~min}$.

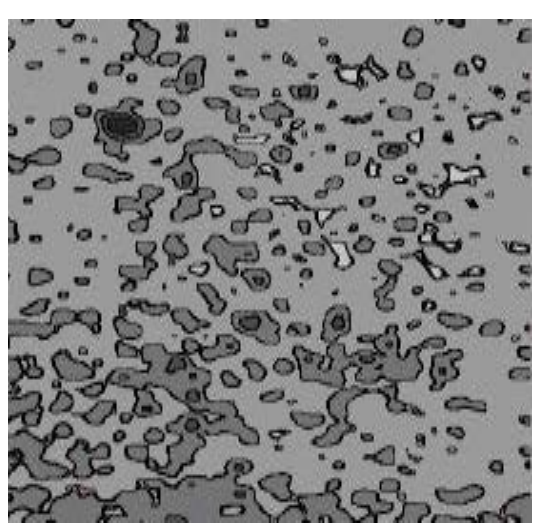

(a)

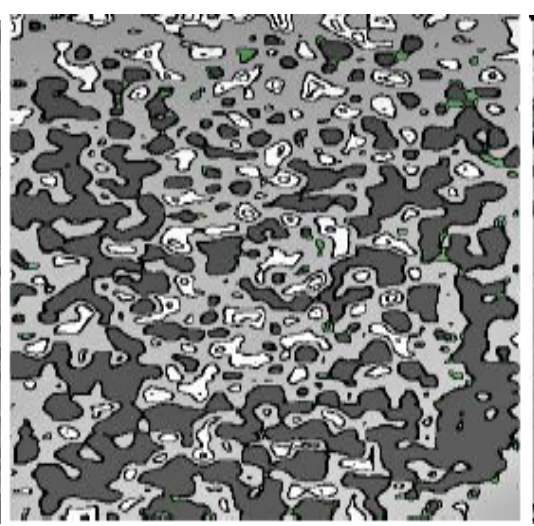

(b)

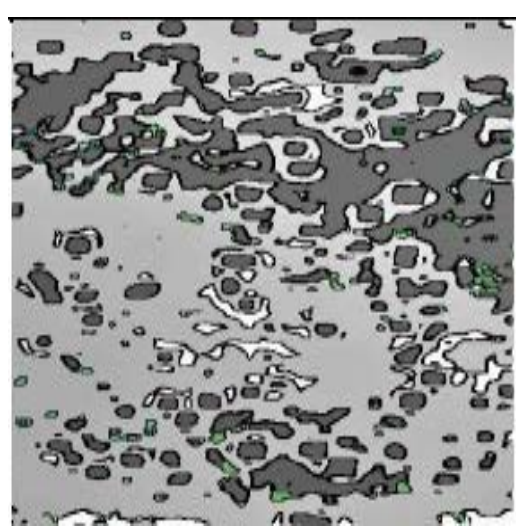

(c)

Figure 9. (a), (b) and (c): JSMI for Si wafer by $\mathrm{Al}$ mesh with $20 \mathrm{~h} / \mathrm{in}$ after coating process at room temperature with scan size of $10 \times 10 \mu \mathrm{m}^{2}$. (a) $t=40 \mathrm{~min}$; (b) $t=60 \mathrm{~min}$; (c) $t=90 \mathrm{~min}$.

filamentary-shaped fractal particles formed as shown in Figures 9(a)-(c).

The particle growth process is the cornerstone_for the coating process that can be discussed as follows: the Ar ${ }^{+}$ 
ions are accelerated onto the substrate at high kinetic energy. When the ions strike the surface atoms, momentum transfer takes places, and the atoms are knocked out of the surface and into the gas phase, where they are pumped away. Taking into consideration that the sputtered atoms (from Al mesh, and surface of the Si wafer [17], or the polymer of the organic material of the dielectric or material between the electrodes, or by flaking off deposited films from wall surfaces [18] [19]) can be recondensed onto a nearby region (substrate) to form the particle growth and then the coating process, thus sputtering can be used to deposit and coating.

About the change of the particulate shape may be related to the coating rate and the coating profile, where the thickness of the polymer layer and the distance between the particulates can change the coating reaction from the compact shape (spherical change as for $20 \mathrm{~h} / \mathrm{in}$ ) to filamentary shape as for $8 \mathrm{~h} / \mathrm{in}$, if the particulate size reach to a critical diameter $(90-120 \mathrm{~nm})$ [20]-[22].

\subsection{Coating Rate Measurements}

By weighting the sample after each run (each plasma coating process) taking into account that coating rate equal to:

$$
\text { Coating rate }=\frac{\mathrm{d} M}{\mathrm{~d} t}=\frac{\text { mass increament }}{Q}=\Delta m / \text { It }
$$

where the charge (Q) by colum equal to $Q=I \times t$, and the typical data were used as the frequency $(f)=1 \mathrm{KHz}=$ $1000 \mathrm{~Hz}$, the repetition rate $=1 \mathrm{~ms}=1 / f, t=$ duration time $\times$ repetition rate $=50 \mu \mathrm{s} \times 1000$, thus $t=(50 \mu \mathrm{s} \times$ $1000 \times 60 \times$ actual time $) \mathrm{sec}, I=50 \mathrm{~mA}$ at low pressure $0.6 \mathrm{mbar}$ and voltage $(V=1000$ volt and mass of the sample $\left(m_{s}\right)$ was 1.4 gram).

On the other hand, the production rate can be computed as follows: The total mass of a particulate cloud is

$$
M=\frac{4}{3} \pi R^{3} \rho n_{d} V
$$

where $R$ and $\rho$ are the particle radius and mass density, respectively, $n_{d}$ is the particles number, and $V$ is the volume occupied by the cloud, and the number of particles $n_{d}$, in air as well as under vacuum is calculated by the formula [23]:

$$
n_{d}=\frac{4}{3} \pi n_{e} \lambda_{D}^{3}
$$

The coating production rate is found by dividing $M$ by the growth cycle period ( $\left.\frac{\mathrm{d} M}{\mathrm{~d} t}\right)$ using Equation (4), furthermore particles radius $(R)$ for 20 h/in and 8 h/in can be calculated from Table 1. As illustrated in Figure 10 it is clear that particles radius for both type of mesh controllers (20 h/in and $8 \mathrm{~h} / \mathrm{in})$ in the range of nanometer and increases with time nodded for coating process, moreover the radius of the particle for $20 \mathrm{~h} / \mathrm{in}$ about 10 times larger than for $8 \mathrm{~h} / \mathrm{in}$, In spite of the starting of the coating process of $8 \mathrm{~h} / \mathrm{in}$ is faster than that of $20 \mathrm{~h} / \mathrm{in}$ by 10 minutes. Then the coating process prefers 20 h/in to 8 h/in this may be due to the electron-neutral particles

Table 1. Computing the particles radius $(R)$ for $20 \mathrm{~h} / \mathrm{in}$ and $8 \mathrm{~h} / \mathrm{in}$.

\begin{tabular}{ccccc}
\hline Coating Time (min.) & Mass Increment $(\boldsymbol{\mu} \cdot \mathbf{g m})$ & $\begin{array}{c}\text { Coating Rate } \\
(\boldsymbol{\mu} \cdot \mathbf{g m} / \text { Coul. })\end{array}$ & $\begin{array}{c}\text { Particle Radius (nm) } \\
\text { for } \mathbf{2 0} \mathbf{~ h / i n ~}\end{array}$ & $\begin{array}{c}\text { Particle Radius (nm) } \\
\text { for } \mathbf{~ h} \text { /in }\end{array}$ \\
\hline 0 & - & - & - & - \\
40 & 22 & 3.66 & 4.67 & - \\
50 & 35 & 4.66 & 104 & 9.2 \\
60 & 47 & 5.22 & 140 & 13 \\
70 & 60 & 5.71 & 179 & 23 \\
90 & 84 & 6.22 & 251 & 28.8 \\
\hline
\end{tabular}




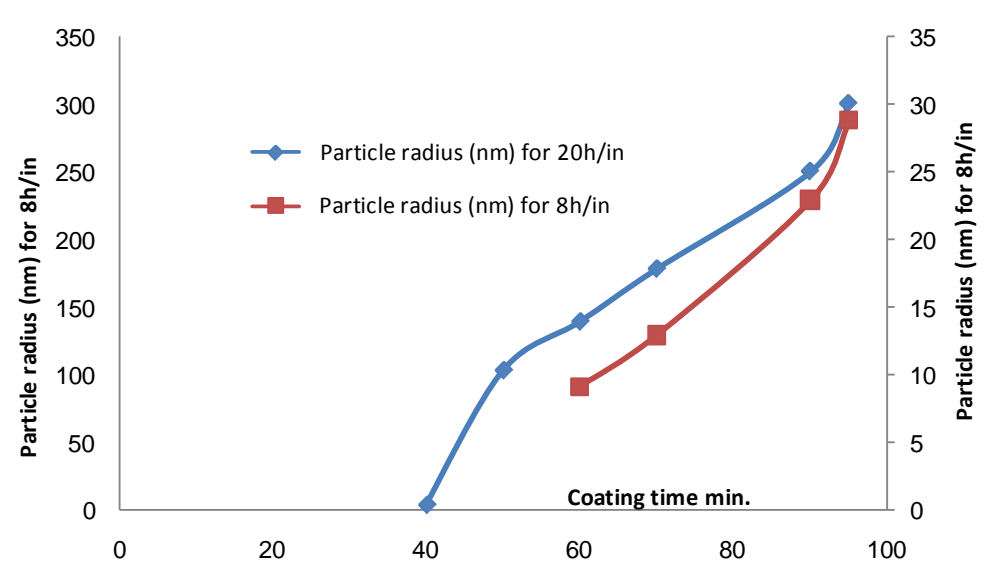

Figure 10. Comparison between the particle radii for meshes with $20 \mathrm{~h} / \mathrm{in}$ and $8 \mathrm{~h} / \mathrm{in}$ for different coating time.

collision frequency $v_{e-n}$ is small and the mean free path $\lambda_{e-n}$ is large for $20 \mathrm{~h} / \mathrm{in}$ than $8 \mathrm{~h} / \mathrm{in}$, respectively. Hence, the loss of electron energy is low for $20 \mathrm{~h} / \mathrm{in}$ than $8 \mathrm{~h} / \mathrm{in}$, where the rate of plasma loss by diffusion coefficient $D_{i}$ is given by $D_{e}=K T / m v_{p}$ and this point will be discussed briefly in the future articles.

\section{Conclusions}

Ultra low frequency of plasma (ULFP) discharge has been experimentally investigated at very low pressure 0.6 mbar and a small distance between electrodes to distinguish between the two different glow discharges produced by two different cathode electrode configurations of a perforated aluminum $(\mathrm{Al})$ wire meshes through measuring plasma parameters for both cases such as current temporal variations, breakdown voltages, and applied electric field values.

Results indicated that small diameter holes of perforated aluminum $(0.3 \mathrm{~mm})$, which indicated mesh with 20 $\mathrm{h} / \mathrm{in}$, the glow discharge produced is more stable glow discharge than bigger holes $(3 \mathrm{~mm})$, which indicated mesh with 20 h/in, i.e. hole number and diameter both have an influence on the glow discharge stability and the preliminary experimental results.

Sharp axial decrements for electron Temperature $\left(T_{e}\right)$ by $20 \mathrm{~h} / \mathrm{in}$ are less than those created by $8 \mathrm{~h} / \mathrm{in}$. In contrast sharp axial increments for electron density $\left(N_{e}\right)$, by $20 \mathrm{~h} / \mathrm{in}$ are more than by those created by $8 \mathrm{~h} / \mathrm{in}$. In our sputtering discharge, nano particles growth with different shape can be obtained: spherical shape particle by 20 $\mathrm{h} / \mathrm{in}$, and filamentary-shaped fractal particles by $8 \mathrm{~h} / \mathrm{in}$ furthermore coating process begins after about $40 \mathrm{mi}-$ nutes for $20 \mathrm{~h} / \mathrm{in}$ and after about 60 minutes for $8 \mathrm{~h} / \mathrm{in}$, this delay in the process due to the start process to be etching and then turn to coating.

The coating process prefers $20 \mathrm{~h} / \mathrm{in}$ to $8 \mathrm{~h} / \mathrm{in}$ due to particle radius growth in different mesh control sputtering discharge increases as the number of holes per inch increases from 8 holes to 20 holes, where particles radius growth for $20 \mathrm{~h} / \mathrm{in}$ was in the range of 4.67 - $301 \mathrm{~nm}$ during exposure time 40 - $95 \mathrm{~min}$, and for $8 \mathrm{~h} / \mathrm{in}$ was in the range of 9.2 - $28.8 \mathrm{~nm}$ during exposure time 60 - $95 \mathrm{~min}$.

\section{References}

[1] Lommatzsch, U., Pasedag, D., Baalmann, A., Ellinghorst, G. and Wagner, H. (2007) Plasma Processes and Polymers, 4, S1041- S1045.

[2] Goree, J. (1994) Plasma Sources Science and Technology, 3, 400. http://dx.doi.org/10.1088/0963-0252/3/3/025

[3] Bai, K., Hong, J., You, S., Choi, C. and Chang, H. (2002) Physics of Plasmas, 9, 1025. http://dx.doi.org/10.1063/1.1436129

[4] Galaly, A.R. and El Akshar, F.F. (2013) Physica Scripta, 88, Article ID: 065503. http://dx.doi.org/10.1088/0031-8949/88/06/065503

[5] Rax, J.M. (2007) Physique des Plasmas. Dundod, Paris.

[6] Samsonov, D. and Goree, J. (1999) Journal of Vacuum Science \& Technology A, 17, 2835. 
http://dx.doi.org/10.1116/1.581951

[7] Kim, H.U., Yi, C. and Rhee, S.W. (2004) Journal of Materials Science: Materials in Electronics, 15, 37-41 http://dx.doi.org/10.1023/A:1026240904706

[8] Galaly, A.R., Elakshar, F.F. and Atta Khedr, M.A. (2013) Materials Science Forum, 50, 756.

[9] Bogaerts, A., Neyts, E., Gijbels, R. and Mullen, J. (2002) Spectrochimica Acta, 57B, 609.

[10] Haacke, M. and Pietsch, G.J. (2000) Some Features of Dielectric Barrier Discharge. Proc. 13th Int. Conf. Gas Discharges \& Their Applications, Glasgow, 267-270.

[11] Pustylnik, M., Ohno, N. and Takamura, S. (2006) Japanese Journal of Applied Physics, 45, 926-932. http://dx.doi.org/10.1143/JJAP.45.926

[12] McWhirter, R.W.P. (1965) Plasma Diagnostic Techniques. Academic Press, New York, 201.

[13] Chen, F.F., Leonard, S. and Huddlestone, E. (1965) Plasma Diagnostic Techniques. Academic Press, New York.

[14] Brown, S.C. (1966) Introduction to Electrical Discharges in Gases. Wiley, New York.

[15] Chapman, B. (1980) Glow Discharges Processes. Wiley, New York.

[16] Hong, J.I., Seo, S.H., Kim, S.S., Yoon, N.S., Chang, C.S. and Chang, H.Y. (1999) Physics of Plasmas, 6, 1017. http://dx.doi.org/10.1063/1.873342

[17] Hoekstra, R.J. and Kushner, M.J. (1998) Journal of Vacuum Science \& Technology B, 16, 2102. http://dx.doi.org/10.1116/1.590135

[18] Sirghia, L., Hatanaka, Y. and Popa, G. (2002) Journal of Applied Physics, 91, 4026-4032.

[19] Buntat, Z., Harry, J.E. and Smith, I.R. (2007) Elektrika, 9, 60-65.

[20] Kogelschatz, U. (2003) Plasma Chemistry and Plasma Processing, 23, 1-46. http://dx.doi.org/10.1023/A:1022470901385

[21] Parks, G.K. (2004) Physics of Space Plasmas. Addison Wesley, Redwood City.

[22] Chen, X.B., Qiu, H., Qian, H., Wu, P., Wang, F.P., Pan, L.Q. and Tian, Y. (2004) Vacuum, 75, 217-223. http://dx.doi.org/10.1016/j.vacuum.2004.03.001

[23] Eser, E. and Ogilvie, R.E. (1978) Journal of Vacuum Science and Technology, 15, 199. http://dx.doi.org/10.1116/1.569454 